Cadernos de Clio, Curitiba, v. 10, $\mathrm{n}^{\circ} .1,2019$

\title{
DOENTES E IMUNDOS: A REPRESENTAÇÃO DA MISÉRIA A PARTIR DE DOENÇAS NA INGLATERRA DA REVOLUÇÃO INDUSTRIAL EM OLIVER TWIST, DE CHARLES DICKENS
}

\section{SICK AND FILFHY: THE REPRESENTATION OF MISERY FROM ILLNESS IN ENGLAND OF THE INDUSTRIAL REVOLUTION IN OLIVER TWIST, BY CHARLES DICKENS}

Walter Gibson ${ }^{1}$

Resumo: O trabalho atual tem como objetivo principal analisar a obra de Oliver Twist escrita por Charles Dickens. A partir de uma investigação histórica embasada na perspectiva do movimento literário Romântico do século XIX se buscarão os principais assuntos que a obra aborda e como refletem a sociedade Inglesa durante a Revolução Industrial. A evidenciação do recurso literário utilizado por Dickens também trará à tona os entendimentos e expressões do autor sobre o mundo, e, portanto aproximação com as questões materiais do período.

Palavras-chave: Revolução industrial; Séc. XIX; Oliver Twist; Inglaterra; Romantismo; Charles Dickens.

Abstract: The current work has as main objective to analyze the work of Oliver Twist Written by Charles Dickens. From a historical investigation based on the perspective of the Romantic literary movement of the 19th century, the main subjects that the work addresses and how they reflect English society during the industrial revolution will be sought. The disclosure of the literary resource used by Dickens will also bring to light the author's understandings and expressions about the world, and therefore an approximation with the material issues of the period.

Keywords: Industrial Revolution; 19th century; Oliver Twist; England; Romanticism; Charles Dickens.

\footnotetext{
1 Estudante do $5^{\circ}$ período do curso de História (Licenciatura e Bacharelado) na Universidade Federal do Paraná. É bolsista do grupo PET História UFPR.
} 


\section{Introdução}

Assim como tantos outros romancistas, Charles Dickens foi um intérprete de sua época. Charles John Ruffan Dickens ${ }^{2}$ nasceu no ano de 1812 em uma cidade pequena chamada Pourtsmouth localizada no sul da Inglaterra, a condição social da família era consideravelmente estável durante os primeiros anos de vida de Dickens. Seu pai, funcionário da marinha real mudava-se constantemente de casa devido aos diferentes apontamentos de seu emprego e levava a família junto. As constantes mudanças e o grande número de filhos (sendo Dickens o oitavo descendente dessa família), fizeram com que a família contraísse dívidas, que aos poucos diminuíram sua qualidade de vida.

Já aos 10 anos é interrompida a educação do pequeno Dickens devido à impossibilidade de pagar pela mesma e é trocada a pena pelo trabalho braçal nas fábricas de escurecimento em Londres. Esse momento na vida do romancista é sombrio mas também essencial para compreender a obra Oliver Twist, na qual o trabalho infantil é demonstrado como precário e devastador da inocência infantil, e demonstra a ineficiência da instituições em terminar ou amenizar tal situação, pelo contrário, são denunciados os estabelecimentos estatais que abrigam o trabalho infantil e se ironiza as legislações e o papel delas:

${ }^{2}$ Todas as informações sobre a vida de Charles Dickens foram retiradas da biografia produzida por John Forster: FORSTER, J. The Life Of Charles Dickens. London: J.M. Dent \& Sons, 1928. 
Mandar que Oliver desafiasse estopa era combinar de um modo simples os dois benefícios que lhe prometiam; ele os reconheceu ambos com uma profunda cortesia por instigação do bedel, depois foi levado para uma grande sala do asilo onde, em cama dura, adormeceu soluçando; prova evidente da brandura das leis do nosso venturoso país que não impedem o sono aos pobres. (DICKENS, 2002: p. 08)

John Dickens, pai de Charles Dickens e mantenedor financeiro da família, não consegue controlar a dívida da família e acaba sendo preso em locais específicos do século XIX na Inglaterra, eram prisões onde poderia levar toda a família e se trabalhava até o débito pendente estar completamente liquidado. A aproximação intensa do autor com a miséria e com as instituições sociais e trabalhistas, privadas e governamentais fez com que o autor não somente acumulasse uma compreensão da pobreza e miséria ao seu entorno como mais tarde aplicasse essa convivência nos seus romances.

Somente com 20 anos a vida de Dickens começou a se estabilizar, confiante em uma carreira promissora o autor tenta ingressar no teatro, não consegue mas dentro desse meio conquista contatos que o levarão para a produção jornalística. Já em 1836, com uma posição econômica mais confortável que a anterior, começa a produzir Oliver Twist. No período do século XIX era comum os livros não serem entregues completos, mas em partes de capítulos publicados periodicamente em jornais ou revistas. É o caso da obra analisada nesse trabalho, que teve seus 53 capítulos publicados mensalmente na revista Bentley's Miscellany de fevereiro de 1837 até abril de 1839. 
A obra Oliver Twist foi o primeiro romance na Inglaterra com um protagonista infantil, tendo como foco a trajetória de vida do pequeno Oliver Twist. Seu pano de fundo é a época vitoriana da Inglaterra com enfoque nos locais periféricos das cidades onde os pobres e os miseráveis circulam, mudando somente ao final do livro quando Oliver, ao descobrir que é o herdeiro de uma família pequeno burguesa conquista seus direitos como tal e vive confortavelmente com o amigo próximo de seu pai o sr. Brownlow.

O livro em si caracteriza a obra do autor e traz o estilo de escrita assim como as principais afluências de suas diversas outras obras. Os personagens caricatos trazem pontos importantes na obra do autor, que muitas vezes se utiliza de maniqueísmos para tratar cada integrante de seu romance como demonstra Susan Meyer e, seu artigo sobre antissemitismo e literatura Dickensiana: sendo Oliver Twist, por exemplo, totalmente incorruptível e inocente ao passo de que Fagin, traz não somente a completa malícia como também o estereótipo de judeu ganancioso do século XIX (MEYER, 2005). O recurso da ironia, assim como as pesadas críticas a sociedade vitoriana, trazem o cunho pessoal como uma forte indicação de que o autor propunha algo em sua obra em contrapartida a essa miséria relatada, que são os valores e costumes da pequena burguesia. Muito mais que uma crítica econômica, Dickens se apoiará na crítica moral, considerando mais que a degeneração ética é papel principal para o alastramento da miséria do que as grandes mudanças econômicas do período industrial, apesar de não ignorar e considerar essa importante. É nessa caracterização dos personagens assim como na representação da 
Cadernos de Clio, Curitiba, v. 10, $\mathrm{n}^{\circ} .1,2019$

miséria que se encontrará o teor de romancista crítico ao sistema vigente e também de indicação de como era a situação dos trabalhadores no período e um esboço das doenças que afetavam tal grupo.

Para uma análise histórica e de aproximação da obra para o contexto social do autor se utilizarão principalmente as obras de Michael Löwy e Robert Sayre Revolta e Melancolia, Peter Gay Represálias Selvagens, Michal Peled Ginsburg Truth and Persuasion: The Language of Realism and of Ideology in "Oliver Twist". Denotando neste artigo, e justificando através dos autores citados que a literatura produzida pelo autor é sim afetada pelos acontecimento em volta do mesmo, colocando sua obra como fora da "identidade neutra", conceito formulado por Roland Barthes (SOUZA apud. BARTHES, 2017: 143).

\section{O que se busca denunciar: estilo e pensamento romântico}

Charles Dickens assim como diversos outros romancistas trará o saudosismo e a nostalgia como grandes fatores em sua obra, e para isso, constrói um ideal utópico de realização do ser humano. Tendo em seu livro um relato dos costumes e do cotidiano o próprio autor relaciona-se diretamente com uma escrita do tempo presente, onde o principal objetivo é filtrar a realidade através do romance (HARTOG, 2017), como Balzac, romancista Francês contemporâneo a Dickens. 
A recusa do utilitarismo ${ }^{3}$ e as relações utilitárias são pontos de partida, colocando a industrialização como degeneradora das relações pessoais. O autor, na obra Oliver Twist, representará esse utilitarismo desumano por parte das instituições estatais como a paróquia que o acolhe no começo do livro. Os líderes da paróquia, tratando os pobres e mendicantes como números, indicam o mínimo para se sobreviver e assim transformam em estimativas a forma e a alma humana, despedaçando-a em cálculos para o benefício próprio. A destruição dos valores humanos denunciada pelo romancista de Oliver Twist é sintoma de um descontentamento grande, ou como afirmam Michael Löwy e Robert Sayre:

Ora, são inúmeros os românticos que sentem intuitivamente que todas as características negativas da sociedade moderna religião do Deus Dinheiro que Carlyle chama de "mamonismo"; declínio de todos os valores qualitativos, sociais, religiosos, etc.; dissolução de todos os vínculos humanos qualitativos; morte da imaginação e do romanesco; enfadonha uniformização da vida; relação puramente"utilitária" dos seres humanos entre si e com a natureza - originam-se nessa fonte de corrupção: a quantificação mercantilista. (LOWY; SAYRE, 2015: 59)

A obsessão pelo dinheiro aparece em diversos personagens na obra que são representados como decadentes, sujos e desagradáveis, podem-se citar aqui personagens: a Senhora Mann, que cuida de crianças para

${ }^{3}$ Como Afirma Bobbio, Em seu dicionário de Politica: “[...]conjunto de doutrinas normativas que têm um conceito comum, o qual afirma que a justificação moral de uma ação depende exclusivamente de sua utilidade, ou seja; do valor das conseqüências a ele conexas." BOBBIO, Norberto; MATEUCCI, Nicola; PASQUINO, Gianfranco. Utilitarismo In.: Dicionário de Política, vol. 1. Brasília: Universidade de Brasília, 2004. p. 1275. 
paróquia e desvia o dinheiro destinado a alimentação dessas para manutenção de luxos; o judeu Fagin que apesar de viver em condições de extrema pobreza não tenta melhorar sua condição com a venda dos bens materiais acumulados ao longo de vários anos de roubo; Monk, meio irmão de Oliver que tenta manter a herança somente para si; os dirigentes da paróquia que no intuito de manterem um grau de vida elevada para si mesmos convertem o dinheiro oferecido pelo Estado em benefício próprio fazendo com que os pobres recebam cada vez menos comida.

A ideia de mecanização e movimentos repetitivos da revolução industrial faz com que os românticos, como Dickens, vejam a mecanização do ser humano como um terror decorrente da racionalização exagerada (LOWY; SAYRE, 2015), exprimida, por exemplo na presença de decoro interminável entre autoridades apenas para fins de reforçar a hierarquia.

Fagin novamente aparece como um personagem de péssimas qualidades e é um dos vilões centrais de Oliver Twist. Sua ganância, suas associações e práticas criminosas assim como sua renúncia a Deus (sendo que até mesmo no último capítulo se recusa a fazer uma oração e se converter para ser salvo do purgatório através das súplicas de Oliver), demonstram a decadência total dessa sociedade, apesar de, em alguns momentos, raros, o mesmo personagem ser tratado como vítima da pobreza.

A uniformização do ser humano, destituído de sua forma única e de seu valor como alma torna-se número ou mão de obra para ser explorada, como as crianças ao trabalharem para a paróquia desfiando estopa, ou 
Oliver Twist sendo utilizado como ferramenta em um roubo de residência planejado por Sikes.

Não é por acaso que Karl Marx terá como um de seus autores prediletos Charles Dickens, ${ }^{4}$ o mesmo denuncia com descrição e método da escrita romântica o que Marx chamará de alienação do trabalho. Representará também a miséria e colocará essa como decorrência da mecanização e do mercantilismo que torna as pessoas menos humanas.

No romance por diversos momentos o retrato de uma sociedade degenerada e de uma alternativa, como a casa do senhor Brownlow serão descritas de formas diferentes para afirmar que tipo de sociedade será fomentada pelo autor, tanto nos aspectos do que não buscar e do que almejar. O mesmo pode-se aplicar aos personagens, principalmente quando esses possuem qualidades negativas como será demonstrada na relação entre o que o autor descreve como miséria e doenças variadas que acometem os personagens, representando não somente um quadro de como o autor via essas regiões periféricas mas também do imaginário das doenças que também faziam parte desse.

\section{Cidades Inglesas no séc. XIX: a subnutrição, a pobreza e as doenças}

A revolução Industrial é reconhecida por diversos historiadores por fomentar uma mudança rápida e repentina na sociedade, em quase todos os campos que essa atinge. Na configuração do trabalho a relação passou a ser somente monetária e o trabalhador passou a ser descartável e substituível

${ }^{4}$ Como Afirma Daniel Puglia sobre a contribuição Marxista e marxiana para a análise de literatura dickensiana na nota de rodapé 9 de sua Tese de Doutorado. (PUGLIA, 2008; 05). 
devido a processos repetitivos dentro das fábricas que não necessariamente requerem empirismo técnico intelectual. No campo intelectual a própria expressão "revolução industrial" trazia um referencial inglês em contrapartida ao francês, que caracterizava uma revolução não violenta e, portanto, superior segundo os pensadores da época, como aponta Christopher Hill (2012). O que fez gerar também um contra movimento no qual se destaca o romantismo e as denúncias ao utilitarismo, elencadas anteriormente, assim como movimentos sociais como o Cartismo e a interpretação da exploração do trabalho como problemática e fundada em contradições no que mais tarde seria a teoria econômica marxiana.

A constituição dos próprios centros produtivos se traduziram na Revolução Industrial, os camponeses, expulsos do campo se aglomeravam nas grandes cidades em busca de emprego. Os mesmos centros não comportavam um número tão grande de mão de obra e por tal motivo formaram-se às pressas, o que fez com que a qualidade de vida desses trabalhadores diminuísse assim como a saúde no local, na qual os vírus, as bactérias e os animais que as transmitiam encontravam um bom catalisador na sujeira e falta de organização.

Habitualmente, as próprias ruas não são planas nem pavimentadas; são sujas, cheias de detritos vegetais e animais, sem esgotos nem canais de escoamento, mas em contrapartida semeadas de charcos estagnados e mal cheirosos. Para além disso, o arejamento torna-se difícil, pela má e confusa construção de todo o bairro, e como aqui vivem muitas pessoas num pequeno espaço, é fácil imaginar o ar que se respira nestes bairros operários. (ENGELS, 1975: 59) 
Com os estudos biológicos e médicos sobre a análise das doenças e pelo que elas são causadas pode-se traçar um paralelo clínico de saúde pública que afirma que quanto maior a higiene, a qualidade de vida e a alimentação de uma população, menores os riscos de contração de doenças epidêmicas bacteriológicas e virais. Infelizmente as cidades da Era Vitoriana eram o completo oposto disso, a maioria delas dependiam de um rio para se livrarem dos dejetos, a população era pobre e numerosa devido aos cercamentos e a formação da classe trabalhadora inglesa e a alimentação era escassa.

Não é incomum nem arbitrário informar que Charles Dickens, assim como Friedrich Engels quando visitou a Inglaterra entre novembro de 1942 até agosto de 1944, presenciaram a proliferação de doenças e miséria que a Revolução Industrial causara. Os dois escrevem, Engels na forma de teoria com A Situação da Classe Trabalhadora na Inglaterra e Dickens em seus diversos romances.

Em Oliver Twist diversas doenças que faziam parte do cotidiano das classes pobres dos grandes centros urbanos são retratadas, a principal delas e que aparece com maior frequência é a inanição, que acarreta a morte por fome. Na primeira residência de Oliver onde a Sra. Mann rouba o dinheiro dedicado à alimentação das crianças algumas não conseguem sobreviver à falta de nutrientes e sucumbem. Já no asilo da mendicidade a comida é restringida e os pobres que dependiam dessa caridade começam a passar fome e morrer por inanição: "Imediatamente estabeleceram como princípio que os pobres pudessem escolher (não se forçava ninguém) uma destas 
coisas: ou morrer de fome lentamente se ficassem no asilo, ou morrer de repente se saíssem para a rua." (DICKENS, 2002: 08)

A mortalidade infantil é um fator que pode indicar a qualidade de vida de um local, o caso de Londres foi levantado por Paul Huck, pesquisador que produziu um estudo sobre mortalidade infantil utilizando registros de 11 paróquias diferentes localizadas na capital inglesa. A primeira conclusão que o autor faz é que nos bairros mais industrializados a mortalidade infantil é maior (HUCK, 1995: 535), o que claramente demonstra uma menor qualidade de vida nesses bairros, que, como Engels anunciou ainda no século XIX, não possuíam alimentos atrativos ou seguros para o consumo (ENGELS, 1975: 60). A morte por fome é tão constante no romance que em certo ponto é naturalizada em uma conversa entre o Bedel e o Sr. Sowerberry do ramo funerário: "Venho — disse ele tomar a medida de duas mulheres que morreram a noite passada./ - $\mathrm{O}$ senhor há de enriquecer[...] Digo-lhe que há de enriquecer —repetiu o Sr. Bumble batendo-lhe amigavelmente no ombro com a bengala." (DICKENS, 2002: 13)

A sífilis, outra doença epidêmica do século XIX, é apresentada através do personagem Tom Chitling, que tinha "olhos pequenos; piscava-os de contínuo; o rosto estava lavrado de bexigas" (DICKENS, 2002: 78), sendo as bexigas citadas por Dickens as lesões causadas pelo vírus no estágio secundário e terciário da doença, que causa marcas permanentes. A doença era conhecida como doença de Bordéis no século XIX, devido a sua transmissão que se dá sobretudo pelo contato sexual, o que reforça o caráter da narrativa que indica o personagem Tom como 
invirtuoso, e que o local que Oliver se encontrava não era seguro, o que contrapõe a noção da inocência com a perversão, sendo a inocência encontrada em Oliver e a perversão no mundo ao seu entorno, que não só se demonstra mas que tenta recrutá-lo, porém o personagem sendo a representação de um sentimento ideal do autor, não é atingido (GINSBURG, 1987).

O Meio irmão de Oliver, Monk, que demonstra moral duvidosa ao longo da obra também é indicado com uma doença que afeta seu corpo e que reforça a retórica de que o personagem é vil naturalmente e que as suas atitudes são condenáveis “[...] a depravação de Monk é natural ao invés de social e é expressada não através de um discurso corrompido mas através de seu corpo, em uma doença." (GINSBURG, 1987: 223)

\section{Representando a Maldade pelas doenças e doentes}

Como já apresentado por Michael Peled Ginsburg, quanto mais próxima a obra da realidade, mais forte seu recurso retórico (GINSBURG, 1987: 221), e Dickens não somente mostra a aproximação com a realidade como molda a mesma para representar virtudes e defeitos. Como veremos a seguir, não somente a descrição do ambiente dos personagens mas também os próprios personagens carregam traços distintos que indicam orientação moral boa ou ruim.

Dickens indica que a maldade não está somente nos ambientes sujos, mas em ambientes onde a moral e a educação supostamente deveriam ser elevadas, quando um personagem de aquisição financeira estável mas moral duvidosa se apresenta o autor do romance o coloca com traços 
marcadamente caricatos. O sr. Bumble que é "gordo e irritadiço" (DICKENS, 2002, p. 5), os membros do conselho paroquial não tem face, mas são retratados como maliciosos pelo recurso da ironia, o que pode apresentar um crítica a um sistema que pode ser igual em outros lugares, ou seja, critica as instância de amparo aos pobres. O Sr. Claypole "[...] tem um nariz de pimentão.” (DICKENS, 2002: 18) e carrega a soberba em seu modo e trejeitos.

Importante aqui ressaltar que a fome para Charles Dickens é representada como um monstro, principalmente para as crianças. Sempre assolando os pobres essa em si é uma maldade completa, que compele as crianças a desafiarem as regras do asilo pedindo mais mingau; que quase obriga Oliver a entrar no mundo do crime; que faz com que matreiro tenha que trabalhar para Fagin. A fome não tem representação nos personagens porque é culpa da sociedade em geral, assim, a doença da inanição é também uma das principais vilãs da obra, pela qual o protagonista trava embates ao longo do enredo.

Outra questão que aparece com certa frequência no livro é a vestimenta das crianças sobre o controle de Fagin, todas elas possuem traços comuns e certa vivacidade do grupo também é demonstrada. Uma característica que exemplifica tal questão é o fato de que as crianças são retratados com roupas maiores que sua estatura, como se as roupas representassem o papel de adulto que não lhes cabia e que é traduzido nas roupas sempre grandes demais.

Também a cidade como construto imundo e disforme faz tanto parte do recurso narrativo retórico que condena esses locais como infelizes 
concomitantemente com a aproximação da representação do real, como vemos no trecho a seguir:

Posto que Oliver fizesse isso mesmo, não deixava de lançar alguns olhares furtivos para os dois lados da rua: era o lugar mais sujo e miserável que ele tinha visto. A rua era estreita e úmida e o ar, carregado de miasmas fétidos. Havia um grande número de lojas pequenas onde as crianças berravam apesar da hora adiantada da noite. Os únicos lugares que pareciam prosperar eram as tavernas, onde irlandeses das fezes do povo, isto é, das fezes da espécie humana, discutiam com todas as forças. Vielas e passagens estreitas deixavam ver algumas casas miseráveis, diante das quais homens e mulheres embriagados rolavam na lama da rua; e às vezes saíam com precaução desses antros indivíduos de cara sinistra, cujas intenções não pareciam ser louváveis nem tranqüilizadoras. (DICKENS, 2002: 31)

A todo momento do romance são encontradas vielas estreitas onde a sujeira é a principal presença assim como o ar sinistro. Essas ruas provavelmente pertencem a bairros industriais onde a pobreza era demarcada como afirmara Engels e Huck.

Toda a construção da miséria e da infelicidade tem uma direção de denúncia e ao mesmo tempo ajuda a formular o bom, se tudo que é horrível na obra dá-se de encontro com as vielas escuras e com Fagin, Sikes e o crime, é produzido o contrário quando a trama insere o sr. Brownlow, criando a dicotomia entre o bem e o mal. Dickens não buscava a realização da bondade humana e da sociedade melhor através de revoluções, mas sim de uma guinada moral. Não é por acaso que Brownlow representa, assim como descrito pela historiadora Marion Brepohl o típico pequeno burguês virtuoso, que conserva os sentimentos e consegue conciliá-los com o 
Cadernos de Clio, Curitiba, v. 10, $\mathrm{n}^{\circ} .1,2019$

mundo reduzido aos processos manuais e aos problemas da revolução industrial. (BREPOHL, 2010)

A pequena burguesia e a humanidade conservada nessa através do ideal romântico representa a guinada moral de que a sociedade vitoriana precisa para sair do obscurantismo. O cotidiano e a valorização do conforto simples assim como a tranquilidade das relações familiares são a contrapartida na qual Dickens coloca sua nostalgia. Sendo as doenças e os problemas econômicos vivendo no lugar externo ao conforto do lar, que passa a ser antro sagrado da convivência harmônica e do ideal da boa moral.

\section{Considerações Finais}

No artigo não só se tratou da vida e obra Oliver Twist de Dickens, como se defendeu a importância de seu contexto na transposição das experiências de sua vida, dando traços de uma realidade sombria e penosa a ficção dos pequenos protagonistas incorruptíveis. Entendemos também que através da caricatura de personagens podemos delimitar uma bússola moral do autor, que transpõe a sujeira e a doença externa de suas personagens para defeitos internos, de ação e participação no mundo. Esse total de feitos, compostos em obras aclamadas fazem de Dickens, junto a tantos outros como William Shakespeare e Lewis Caroll, um expoente importante da literatura inglesa.

Não é por acaso que Charles Dickens é considerado até os dias atuais como um dos maiores romancistas ingleses. Tendo escrito mais de 20 obras se tornou um fenômeno em sua época, sendo um dos autores mais vendidos 
em todo o território do Reino Unido. Utilizou de seu conhecimento empírico sobre pobreza e miséria para retratar uma Londres ignorada em diversos aspectos, tornou-se até certo ponto uma voz dos oprimidos que a alta sociedade vitoriana insistia em ignorar.

O alcance de seus livro podem ser medidos, por exemplo, na quantidade de cópias vendidas e também nas inúmeras adaptações cinematográficas que suas obras renderam. Somente Oliver Twist tem duas adaptações cinematográficas: no século XX (THE ADVENTURES OF OLIVER TWIST, 1997) e no século XXI (OLIVER TWIST, 2005), uma adaptação também cinematográfica em forma de musical (OLIVER!, 1968). Fora outras diversas adaptações que não serão citadas aqui.

Todo esse interesse imenso nas obras pode não somente demonstrar o impacto que Dickens teve no imaginário da revolução industrial tida como populações enormes de miseráveis, doentes, pobres, sujos, infestada de delinquentes e excluídos socialmente que é construído hoje, como também suas denúncias a um mundo injusto traduzidas a uma simpatia de injustiças no mundo contemporâneo.

\section{Bibliografia}

BREPOHL, Marion. Karl May e o bom civilizador. In: BREPOHL, Marion. Imaginação Literária e Politica: Os Alemães e o Imperialismo

DE SOUZA, D. C. (2017). A MORTE DO AUTOR DE ROLAND BARTHES: ECOS MUSICAIS. Revista Ribanceira, Belém, n. 9, jun, 2017, pp.141-149

DICKENS, Charles. Oliver Twist. Tradução de Machado de Assis e Ricardo Lísias, 1ª . Ed., São Paulo Hedra, 2002. Disponível em: 
https:/www.google.com.br/url?sa=t\&rct=j\&q=\&esrc=s\&source=web\&cd= $1 \& \mathrm{cad}=$ rja\&uact $=8 \&$ ved $=2$ ahUKEwi-y_aeo-PiAhX1ILkGHfQ5D8IQFjAA egQICBAC\&url=http\%3A\%2F\%2Fmachado.mec.gov.br\%2Fobra-complet a-lista\%2Fitem\%2Fdownload\%2F120 031 c6366de1a2c89eabf5d83e19285 36\&usg=AOvVaw21WDMy4zToJ18fexqXbOZ6. Acesso em: 04/05/2019.

ENGELS, F. As Grandes Cidades In. A situação da classe trabalhadora na Inglaterra. São Paulo: Global, 1986.

FORSTER, J. The Life Of Charles Dickens. London: J.M. Dent \& Sons, 1928.

GAY, P. Represálias selvagens: Realidade e ficção na literatura de Charles Dickens, Gustave Flaubert e Thomas Mann, São Paulo: Companhia das Letras, 2010.

GINSBURG, Michal Peled. Truth and Persuasion: The Language of Realism and of Ideology in 'Oliver Twist'. NOVEL: A Forum on Fiction, vol. 20, no. 3, 1987, pp. 220-236. JSTOR, www.jstor.org/stable/1345676.

HARTOG, F. Crer em história. Belo Horizonte: Autêntica Editora, 2017.

HILL, Christopher. O século das revoluções 1603 -1714. São Paulo: UNESP, 2012.

HUCK, P. (1995). Infant Mortality and Living Standards of English Workers During the Industrial Revolution. The Journal of Economic History, 55(3), 528-550. doi:10.1017/S0022050700041620

LÖWY, M. \& SAYRE, R. Revolta e melancolia. São Paulo: Boitempo, 2015.

MEYER, Susan. Antisemitism and Social Critique in Dickens's Oliver Twist. Victorian Literature and Culture, 2005, v. 33, n. 1, p. 239-252.

Oliver!. Carol Reed (dir.), Reino Unido: Columbia Films S.A. 1968 (153 $\min )$.

Oliver Twist. Roman Polanski (dir), EUA: Sony Pictures, 2005. (130 min). 
Cadernos de Clio, Curitiba, v. 10, $\mathrm{n}^{\circ} .1,2019$

ORWELL, George. Charles Dickens in the decline of the English murder and other Essays. Harmondsworth: Penguin, 1965.

PUGLIA, Daniel. Charles Dickens: Um escritor no centro do capitalismo. São Paulo: Universidade de São Paulo (tese de doutoramento). Disponível em:

$<$ https://www.teses.usp.br/teses/disponiveis/8/8147/tde-06112007-103719/ publico/TESE_DANIEL_PUGLIA.pdf> Acesso em: 02/06/2019. 2008.

The Adventures of Oliver Twist. Tony Bill (dir.), The Walt Disney Company, 1997. (91 min).

Recebido: $19 / 08 / 2019$

Aceito: 10/07/2020 